\title{
Aerobiologia de Cercospora kikuchii
}

\author{
Aerobiology of Cercospora kikuchii
}

\section{Ângela Sathiko Kudo ${ }^{I}$ Luiz Eduardo Bassay Blum ${ }^{I *}$ Marcello Arrais Lima ${ }^{I I}$}

\section{RESUMO}

Neste estudo, foram quantificados os conídios de Cercospora kikuchii [crestamento foliar em soja (Glycine max)] presentes no ar, sua relação com a intensidade da doença e com os fatores ambientais [temperatura, umidade relativa do ar (UR), precipitação e molhamento foliar] no período de novembro a março de 2006/07 e 2007/08 em Brasília, DF. Para tanto, foi instalada uma armadilha volumétrica captaesporos 'Burkard' de sete dias em campo experimental com soja. Houve maior captura de conídios no período diurno, com mais de $60 \%$ dos esporos coletados entre $8 \mathrm{~h}$ e $15 \mathrm{~h}$. Os dados climáticos variaram de acordo com a safra, mas, de modo geral, em ambos os experimentos, o período de maior captura de esporos ocorreu quando houve redução da precipitação e do molhamento foliar. A UR acima de $80 \%$ e temperatura entre 20 e $24^{\circ} \mathrm{C}$ foram mais favoráveis para a captura de conídios e a intensidade do crestamento foliar. Nos dois anos de avaliação, a maior quantidade de esporo capturado ocorreu quando a soja se apresentava no estádio R6-R7, assim como a intensidade da doença foi maior após o início do estágio reprodutivo da cultura. Apesar da quantidade de conídio capturado em 2006/07 ter sido maior que em 2007/ 08, o padrão da flutuação aérea de conídios foi semelhante.

Palavras-chave: crestamento foliar de cercospora, Glycine max, armadilha capta-esporos.

\section{ABSTRACT}

The objective of this study was to evaluate the relation of airborne released conidia of Cercospora kikuchii [cercospora leaf blight of soybean (Glycine max)] with the disease intensity and some environmental factors [temperature, relative humidity $(\mathrm{RH})$, precipitation and leaf wetness period) under experimental field conditions in Brasília, DF, Brazil. The evaluation was from November to March of 2006/07 and 2007/ 08. Data for the amount of airborne conidia were collected using a Burkard's seven-day volumetric spore trap set in a field with soybean. Most of the conidia were collected during the day, with over $60 \%$ of the spores collected between $8 \mathrm{~h}$ and $15 \mathrm{~h}$. Climatic data varied according to the crop period, but for both periods the highest amount of spores occurred with reduction of precipitation and leaf wetness period. $\mathrm{RH}$ above $80 \%$ and temperature from 20 to $24^{\circ} \mathrm{C}$ were more favorable to capture of conidia and disease intensity. For both crop period of evaluation the major amount of spores were collected when plant stage was R6-R7, as well as, disease intensity increased after beginning of reproductive stage of soybean. Although the number of captured conidia in the 2006/07 crop period was higher than in 2007/08, the variation of fluctuation of airborne spores occurred similarly.

Key words: Cercospora leaf blight, Glycine max, environmental factors.

\section{INTRODUÇÃO}

Dentre as principais doenças da soja [Glycine max (L.) Merr.] no Brasil, o crestamento foliar [Cercospora kikuchii (MATSUMOTO \& TOMOYASU) Gardner] tem se destacado pelos danos que pode causar (JULIATTI et al., 2004). Doenças foliares são influenciadas pelas condições meteorológicas e ambientais locais, tais como, molhamento foliar, temperatura, umidade relativa do ar

${ }^{\mathrm{I} C o n s e l h o ~ N a c i o n a l ~ d e ~ D e s e n v o l v i m e n t o ~ C i e n t i ́ f i c o ~ e ~ T e c n o l o ́ g i c o ~(C N P q), ~ B r a s i ́ l i a, ~ D F, ~ B r a s i l . ~}$

"Departamento de Fitopatologia, Universidade de Brasília (UnB), Campus Darcy Ribeiro, 70910-900, Brasília, DF, Brasil. E-mail: luizblum@unb.br.*Autor para correspondência. 
e precipitação, e que são importantes para a infecção, esporulação e dispersão de esporos (VALE et al., 2004). Há indicativos de que existem diferenças na periodicidade intradiurna de esporos de alguns fungos, que, além dos fatores meteorológicos, podem ser influenciadas pela estação do ano, situação geográfica, distância das fontes de produção de esporos e tipo de vegetação (STEPALSKA \& WOLEK, 2009). Desse modo, o entendimento dos fatores que influenciam no desenvolvimento das doenças é essencial para tomada de decisões para o manejo adequado.

ROSSI et al. (2005) verificaram que o aumento da concentração de esporos de Stemphylium vesicarium em área com cultura de pêra foi correlacionado com umidade relativa do ar, período de molhamento foliar no início da manhã e com o aumento do vento no final da manhã e à tarde. Segundo STEPALSKA \& WOLEK (2005), trabalhos realizados na Polônia indicaram que a temperatura é a variável mais influente na concentração aérea de esporos de Alternaria, Botrytis e Cladosporium, com correlações significativas e positivas.

Em relação a $\boldsymbol{C}$. kikuchii, SCHUH (1991) relatou que um período mínimo de $18 \mathrm{~h}$ de molhamento foliar é necessário para infecção da folha e da vagem de soja pelo fungo na Pensilvânia, EUA. O mesmo autor também observou que a temperatura e a umidade relativa do ar influenciaram na severidade da doença definida pela porcentagem de área foliar com lesões. WALTERS (1980) relatou que a expressão de sintomas de infecção foliar por $\boldsymbol{C}$. kikuchii sob condições de campo geralmente se torna visível no começo e durante o enchimento de grãos (estádios R5 a R8, de acordo com FEHR \& CAVINESS, 1981). Há relato indicando que as condições climáticas favoráveis à ocorrência de crestamento foliar são chuvas frequentes e temperaturas entre $22^{\circ}$ e $30^{\circ}$ (EMBRAPA, 2008). No entanto, dados sobre os fatores ambientais que influenciam na expressão do crestamento foliar, principalmente em campo, e da aerobiologia do fungo ainda são escassos ou inexistentes no Brasil.

Assim, o objetivo deste trabalho foi avaliar a liberação aérea de conídios, sua relação com os danos provocados pelo crestamento foliar em soja e com os fatores ambientais que podem influenciar no progresso da doença sob condições de campo.

\section{MATERIAL E MÉTODOS}

O estudo foi realizado na Estação Experimental de Biologia da Universidade de Brasília, Brasília, DF, entre novembro e março de 2006/07 e 07/ 08. Para determinar o número de conídios de $\boldsymbol{C}$. kikuchii durante o cultivo de soja e o período de liberação de esporos durante o dia, foi instalada uma armadilha capta-esporos 'Burkard' de sete dias (Burkard Scientific Instruments, Rickmansworth, Herts, U.K.) em campo, contendo os genótipos susceptíveis de soja GT04-8091RR (Plantio 10-15/11/06) e GT04-9180 (Plantio 10-15/ 11/07).

A armadilha com sucção de ar a $10 \mathrm{~L} \mathrm{~min}^{-1}$ continha um tambor giratório $\left(2 \mathrm{~mm} \mathrm{~h}^{-1}\right)$ com filme plástico adesivo colocado ao seu redor para a captura dos conídios. O adesivo plástico ajustado ao tambor era substituído semanalmente. A leitura diária e horária do número de conídios capturados foi feita a cada sete dias, mediante a montagem de sete lâminas para microscopia, uma para cada dia da semana, com um pedaço de $48 \mathrm{~mm}$ de plástico por lâmina. A montagem das lâminas foi feita utilizando-se corante azul de algodão para visualização dos esporos e, em seguida, observadas ao microscópio ótico (400x). As quantificações de conídios foram feitas no período de 29/11/2006 a 21/3/2007 e de 29/11/2007 a 21/3/2008.

Junto à armadilha de coleta de esporos, foi instalada uma estação meteorológica para medição de temperatura, umidade relativa do ar (UR), precipitação e molhamento foliar. Para quantificação da doença, foram realizadas avaliações de incidência em folíolos (\% de folíolos afetados/parcela) e severidade (estimativa visual da porcentagem de área foliar lesionada). Foram avaliados 24 folíolos por parcela, num total de seis parcelas de $2,5 \mathrm{~m}$ de comprimento, com espaçamento de $50 \mathrm{~cm}$ entre as cinco linhas e 15 plantas $\mathrm{m}^{-1}$. Em 2006/07, foram realizadas nove avaliações semanais durante o período de 18/12/2006 a 18/2/2007 e, em 2007/08, foram realizadas sete avaliações semanais no período de 18/12/2007 a 4/2/2008.

As análises estatísticas foram realizadas utilizando o programa SAS [SAS Institute Inc. (1999)]. Foi feita a correlação entre as diversas variáveis com os dados obtidos, porém foram apresentadas apenas as correlações significativas. As análises de regressão foram executadas quando possível e quando apresentavam alguma provável significância biológica.

\section{RESULTADOS E DISCUSSÃO}

Considerando a captura de conídios ao longo do dia, houve maior concentração destes das $7 \mathrm{~h}$ às 17 h no período de 29/11 a 22/01 (2006/07). No intervalo de 22/01 a 21/03, o horário em que houve maior captura de conídios ocorreu das $7 \mathrm{~h}$ até as $20 \mathrm{~h}$ (Figura 1A). Além disso, mais de $60 \%$ dos esporos foi coletado entre $8 \mathrm{~h}$ e $15 \mathrm{~h}$, tanto em 2006/07 quanto em 2007/08. 

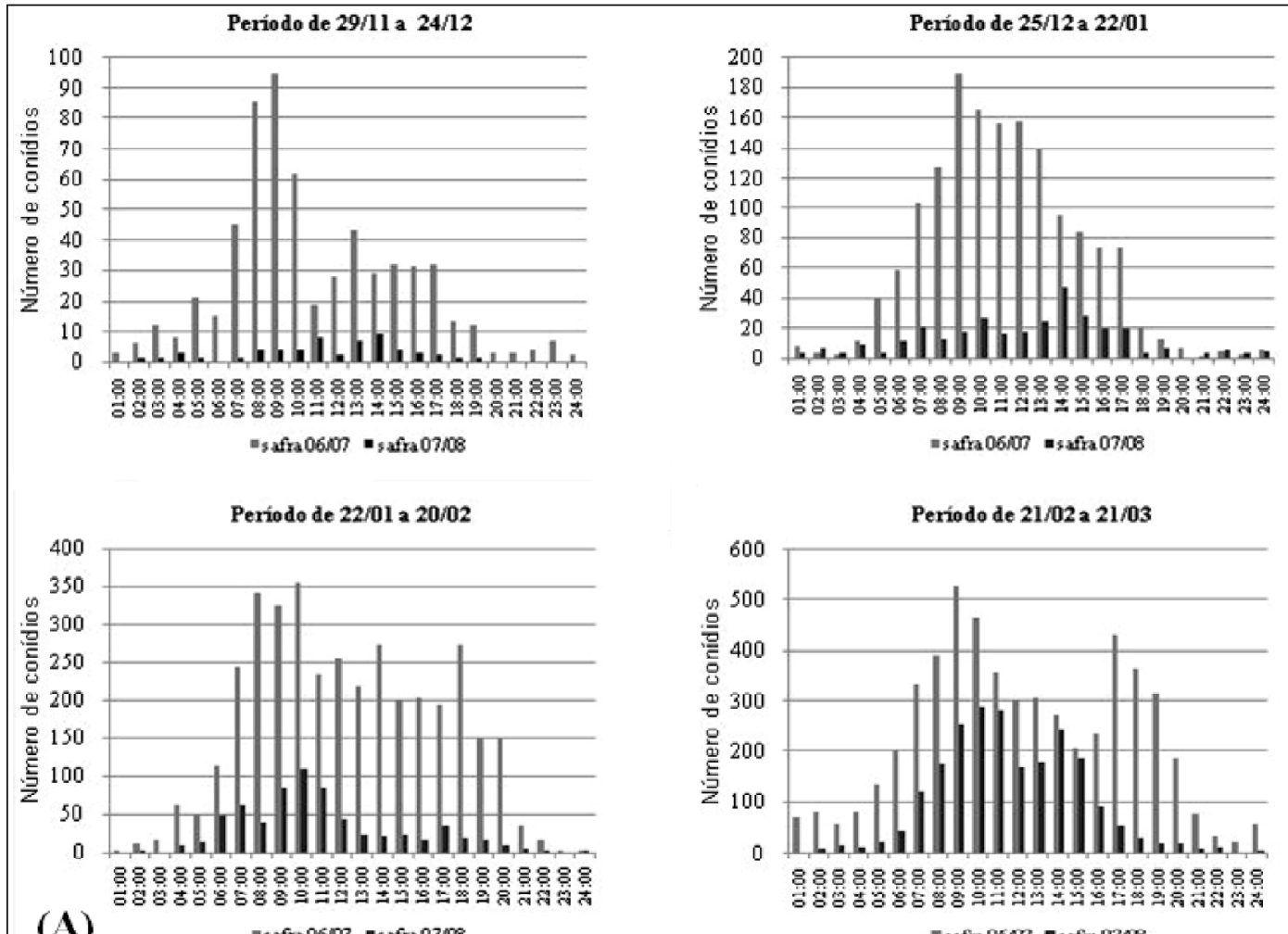

(B)

Safra 2006/07
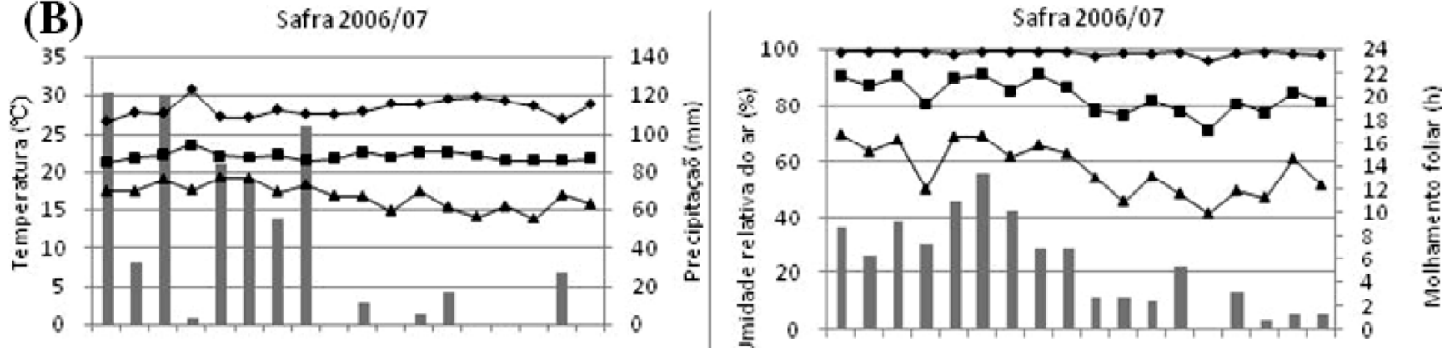

123456789101112131415161713 Semanas $(20 / 11 / 06$ a $21 / 3 / 07)$

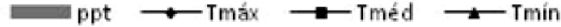

Semanas $(20 / 11 / 06$ a $21 / 03 / 07)$

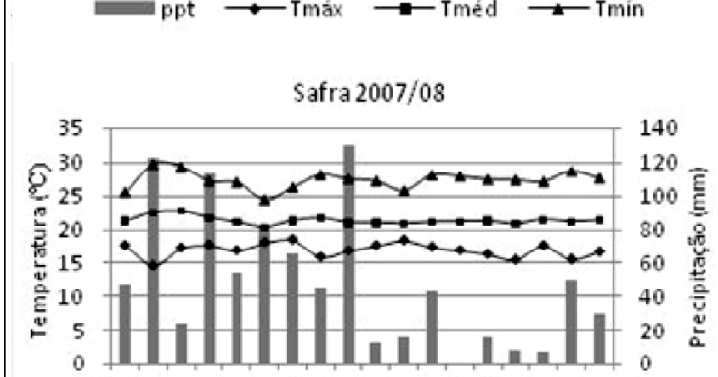

123456789101112131415161718

Semanas $(20 / 11 / 07$ a $21 / 03 / 08)$

—opt $\longrightarrow$ Tmin $\longrightarrow$ Tméd $\longrightarrow$ Tmáx

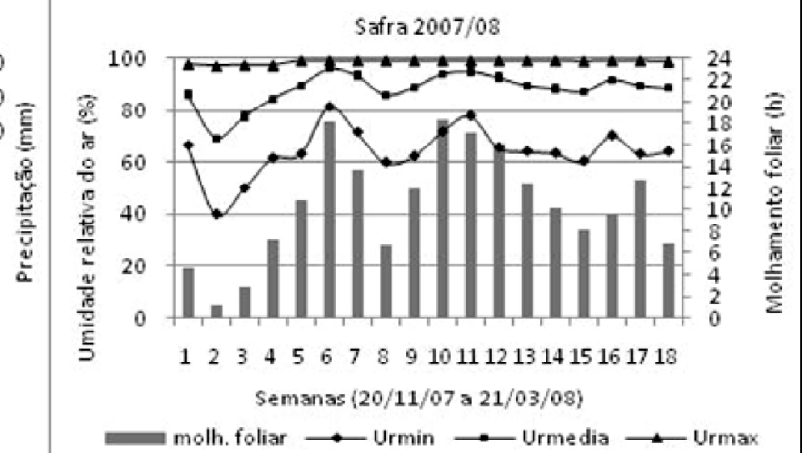

Figura 1 - (A) Número cumulativo total de conídios de Cercospora kikuchii coletados pela armadilha 'Burkard' em razão da hora do dia nas safras 2006/07 e 2007/08. (B) Temperatura (máxima, média e mínima), precipitação pluviométrica (ppt), umidade relativa do ar (máxima, média e mínima) e molhamento foliar durante as safras de 2006/07 e 2007/08 (novembro a março) em campo de soja da Estação Experimental de Biologia da UnB - DF. 
Em 2006/07, o pico de liberação de conídios ocorreu no período da manhã ( 9h), durante o ciclo da soja. Já em 2007/08 houve variação dos períodos de pico de acordo com a fase da cultura, sendo que na primeira metade do ciclo os picos ocorreram à tarde (14h), e na segunda metade os picos ocorreram pela manhã (10h). Esses dados indicam que a variação da concentração de esporos ocorre não só durante o ciclo da soja, mas também ao longo do dia, o que leva à necessidade de constante monitoramento do fungo e da doença.

Na safra 2007/08, além da menor captura de conídios em relação à safra anterior, foi observado também que o período do dia em que houve maior captura de conídios foi mais curto. No primeiro mês de avaliação, poucos conídios foram capturados, indicando que a infecção das plantas pelo patógeno ocorreu mais tardiamente no ciclo da cultura.

SCHUH (1993) comentou que sob condições de campo na Pensilvânia o fungo $\boldsymbol{C}$. kikuchii liberou esporos entre $4 \mathrm{~h}$ e $8 \mathrm{~h}$ e entre $18 \mathrm{~h}$ e $21 \mathrm{~h}$. O primeiro período de esporulação poderia explicar o fato da maior concentração de captura de conídios no presente trabalho ter ocorrido durante a manhã. Embora tenha havido variação na captura de esporos durante o dia, pode-se observar que houve aumento progressivo na quantidade de esporos capturados com o avanço no ciclo da cultura. Houve correlação negativa e regressão significativa do número total de conídios com UR e com molhamento foliar com os dados obtidos na safra 2006/07. Na safra 2007/08, não houve correlação significativa entre as variáveis de dados analisados.

A correlação negativa da quantidade de conídios com a UR e com o molhamento foliar revela que esses fatores são importantes para liberação e consequente captura de esporos. Segundo trabalho desenvolvido por BLUM \& DIANESE (2001), as faixas horárias de maior captura de urediniósporos de Puccinia psidii no jambeiro, entre $9 \mathrm{~h}$ e $15 \mathrm{~h}$, coincidem com os menores valores de UR do dia, significando que eles não estariam aderidos entre si pela umidade $\mathrm{e}$ sujeitos à disseminação eólica, o que também pode ter ocorrido neste trabalho.

Os dados obtidos no presente estudo também coadunam com os relatados por CORREIA \& COSTA (2005), que observaram que o período de maior liberação de esporos de Lasiodiplodia theobromae ocorreu durante os horários de $6 \mathrm{~h}$ às $10 \mathrm{~h}$. Segundo FITT et al. (1989), a liberação dos esporos que são dispersados no ar seco mostra uma periodicidade diurna; frequentemente, os esporos são coletados próximo ao meio dia quando a velocidade do vento é maior, a temperatura é mais elevada e a umidade relativa é menor.
Na safra 2006/07, de um modo geral, houve aumento gradativo da quantidade de conídios capturados durante cada semana de avaliação (Figura 2). No entanto, a maior quantidade de esporos capturados ocorreu após o início do estádio reprodutivo da soja.

De 15 a 21/1/07 e de 12 a 18/2/07 (semanas 9 e 13; Figura 2) ocorreram dois picos na captura de esporos de $\boldsymbol{C}$. kikuchii. No entanto, o período em que houve maior captura de conídios ocorreu de 5/3 a 11/3/ 2007 (semana 16), com as plantas se apresentando no estádio fenológico R6-R7, de acordo com a escala de FEHR \& CAVINESS (1981). Os dois primeiros picos coincidiram com períodos de alta umidade relativa do ar, baixa precipitação e temperatura do ar em torno de $23^{\circ} \mathrm{C}$. Já o terceiro e maior pico foi precedido por um longo período de seca, mas com alta umidade relativa e temperatura entre $22 \mathrm{e} 23^{\circ} \mathrm{C}$ (Figura 1B).

Pode-se observar que a liberação de conídios na safra 2006/07 variou de maneira semelhante à curva da umidade relativa do ar (média e mínima) e inversamente aos períodos de precipitação e molhamento foliar. Já com relaçãoà temperatura, embora a temperatura média tenha apresentado pequena variação $\left(21,1\right.$ a $\left.23,6^{\circ} \mathrm{C}\right)$, o período de maior amplitude térmica corresponde, de modo geral, ao período de maior captura de esporos (Figuras 1 e 2).

No período de 18/12/06 a 25/2/07, foram avaliadas a incidência e severidade do crestamento foliar de cercospora nas plantas de soja (Figura 2), e houve aumento da doença a cada semana, com exceção da sétima e oitava avaliações. Na última avaliação, houve um aumento significativo na incidência (de $0,93 \%$ para $41,66 \%$ ) e na severidade (de $0,0046 \%$ para $1,06 \%)$.

Houve correlação negativa significativa entre quantidade total de conídios do período e temperatura mínima $(\mathrm{r}=-0,68 ; \mathrm{P}=0,01)$, umidade relativa do ar média $(\mathrm{r}=-0,57 ; \mathrm{P}=0,05)$, umidade relativa do ar mínima $(\mathrm{r}=-0,55 ; \mathrm{P}=0,05)$, precipitação $(\mathrm{r}=-0,53 ; \mathrm{P}=0,05)$, período de molhamento foliar $(\mathrm{r}=-0,49 ; \mathrm{P}=0,05)$ e a variável incidência $(\mathrm{r}=0,72 ; \mathrm{P}=0,05)$. Houve também correlação positiva entre as variáveis severidade $\mathrm{e}$ incidência $(r=0,98 ; P=0,01)$. Não houve correlação significativa do número total de conídios com a severidade, mas houve uma tendência de aumento da doença e do número de conídios com o tempo.

Em 2007/08, a quantidade de conídios capturados foi menor e a detecção dos primeiros esporos durante o ciclo da cultura ocorreu mais tardiamente (Figura 2A). Cabe ressaltar que a captura de conídios durante o ciclo da cultura ocorreu de modo semelhante nas duas safras. A maior captura de conídios ocorreu a partir da semana de 29/1 a 4/2/08, com pico na semana de 12/2 a 18/2/08. Em 2007/08, o 


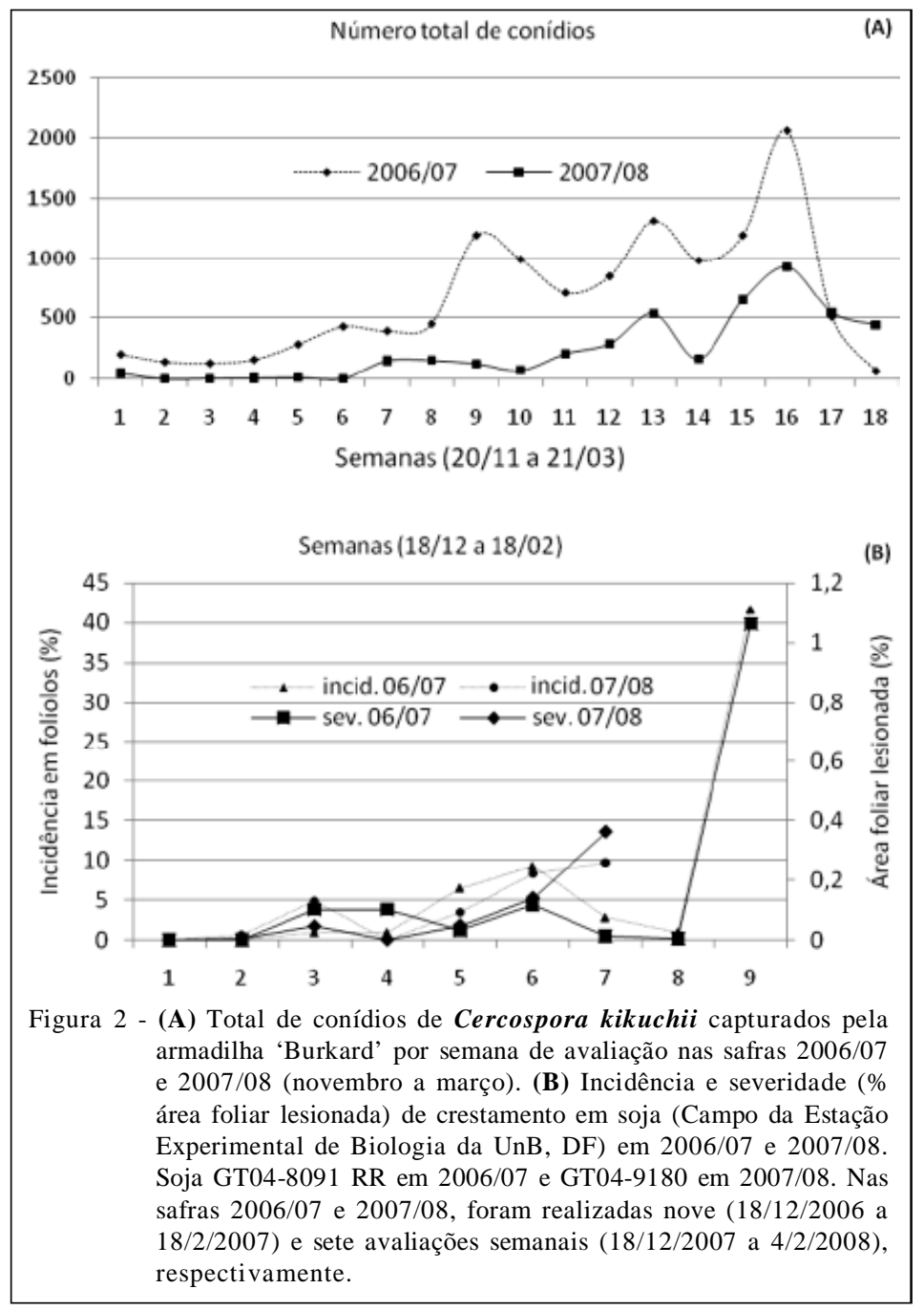

maior número de conídios foi capturado de $5 / 3$ a 11/3/ 2008, quando as plantas se apresentavam no estádio R6-R7.

A severidade e a incidência da doença foram avaliadas durante o período de 18/12/07 a 18/2/08 (Figura 2B). Os valores das duas variáveis aumentaram a cada avaliação (da primeira à última avaliação houve aumento de 0 a $0,45 \%$ na severidade e de 0 a $12,64 \%$ na incidência), correspondendo ao crescente número de conídios capturados, com exceção da 5a e $6^{a}$ avaliações, nas quais houve aumento da doença, mas redução no número de conídios.

Houve correlação negativa significativa entre o total de conídios capturados e a precipitação $(\mathrm{r}=-0,536 ; \mathrm{P}=0,05)$. Períodos precedentes de precipitação favoreceram a formação dos conídios e períodos com baixa precipitação favoreceram a liberação e captura dos esporos.
O período de maior captura de conídios ocorreu após o início do estádio reprodutivo da soja, com a quantidade de doença aumentando a cada avaliação. A maior coleta de conídios ocorreu com as plantas nos estádios R4 a R7 (De fevereiro a meados de março). A redução da quantidade de conídios nas duas últimas coletas de esporos pode ter ocorrido devido à desfolha e seca das plantas no final do ciclo em R7 e R8 (FEHR \& CAVINESS, 1981).

O aumento da quantidade de esporos capturados e da severidade e incidência da doença durante as safras também coincidiram com a redução das chuvas, que ocorreu na segunda quinzena de janeiro de 2007 e de 2008. Foi verificado que houve regressão quadrática significativa entre a quantidade de conídios e a precipitação. A partir de tais resultados, pode-se então inferir que a precipitação tem papel importante no fluxo aéreo de esporos, e consequentemente na sua captura pela armadilha. 
Esses resultados corroboram aqueles anteriormente publicados com outros patossistemas, os quais mostraram que a liberação de esporos pelo vento está diretamente relacionada com os índices de pluviosidade (CORREIA \& COSTA, 2005). HOY et al. (1991) constataram que houve decréscimo na captura de esporos de Ustilago scitaminea, após o aumento de chuvas. BLUM \& DIANESE (2001) observaram uma redução na captura de urediniósporos de $\boldsymbol{P}$. psidii em jambeiro após períodos de chuva. Em adição, CORREIA \& COSTA (2005) observaram que, com precipitações pluviais acima de $80 \mathrm{~mm}$, os conídios de L. theobromae em coqueiro começaram a ser precipitados do ar, e consequentemente resultaram no decréscimo de esporos capturados.

A diferença do número de conídios de uma safra para a seguinte pode ter ocorrido devido a diferenças nos fatores climáticos, posto que em 2007/ 08 houve períodos mais longos de molhamento foliar e de precipitação, maior umidade relativa do ar média e mínima, e temperaturas ligeiramente menores (Figura 1B). ORTH \& SCHUH (1994) obtiveram diferentes resultados nas densidades de inóculo de $\boldsymbol{C}$. kikuchii, capturados por meio de armadilha em duas safras seguidas de soja, em que as quantidades de conídios foram menores na safra de 1992 em relação à safra de 1991, e relataram que tais dados provavelmente resultaram da variação dos fatores ambientais.

A quantidade de doença durante as avaliações também pode ter variado devido às diferenças nos fatores climáticos, embora não tenha havido correlação dessas variáveis com a quantidade de conídios capturados. Segundo SCHUH (1991, 1992, 1993), a infecção por $\boldsymbol{C}$. kikuchii em soja depende muito das condições climáticas e do estádio de desenvolvimento da planta. SCHUH (1991) revelou que a severidade da doença foi mais alta com o aumento do período de molhamento foliar, e ressaltou a importância da UR na germinação dos conídios. SCHUH (1993) relatou que períodos submínimos de molhamento foliar podem reduzir a capacidade de infecção de $\boldsymbol{C}$. kikuchii. Nesse relato, os valores de doença obtidos durante períodos de interrupção de molhamento foliar maiores que $8 \mathrm{~h}$ foram reduzidos. No entanto, quando a UR se apresentou acima de $90 \%$, mesmo durante os períodos de interrupção do molhamento foliar, houve aumento na doença, uma vez que essas condições permitiram a continuidade do desenvolvimento do tubo germinativo do fungo.

Os dados de UR e molhamento foliar obtidos em 2007/08 corroboram os obtidos por SCHUH (1993). Entretanto, em 2006/07 os dados dessas variáveis ambientais não são semelhantes com relação à ocorrência de infecção por $\boldsymbol{C}$. kikuchii, uma vez que a UR média se apresentou próxima de $80 \%$ e os períodos de molhamento foliar não foram mais longos que $8 \mathrm{~h}$ (dados não publicados) nas duas semanas que antecedem o período de maior severidade e incidência. No entanto, as temperaturas médias de todas as avaliações foram entre $20 \mathrm{e} 24^{\circ} \mathrm{C}$, próximas aos $25^{\circ} \mathrm{C}$ que foram relatados por $\mathrm{SCHUH}$ (1991), e que permitem inferir que a temperatura apresenta grande influência no desenvolvimento do crestamento foliar da soja. SCHUH (1991) reportou que a temperatura e a umidade relativa do ar apresentaram influência significativa na severidade da doença, independente do período de molhamento foliar. KOSHIKUMO (2007) observou que a cercosporiose em milho apresentou maior severidade no ano de 2002, no qual a temperatura média foi de $20,4^{\circ} \mathrm{C}$, maior do que em 2004 (média de $18,1^{\circ} \mathrm{C}$ ), e sugeriu que tais resultados ocorreram pelo fato de que, em 2002, a temperatura esteve mais próxima da faixa favorável à doença $\left(22 \mathrm{a} 30^{\circ} \mathrm{C}\right)$.

Vale destacar que os maiores valores de severidade e incidência foram apresentados quando as plantas se apresentavam em estádios susceptíveis à doença, estando mais próximas do final do ciclo (FERREIRA et al., 1979; YORINORI, 1998). Segundo WALTERS (1980), a expressão de sintomas de infecção foliar sob condições de campo geralmente se torna visível no início e durante a fase de enchimento de grãos, raramente ocorrendo antes do estágio R4. GODOY \& CANTERI (2004) relataram que o crestamento foliar em soja foi observado a partir do estágio R6.

Assim, de acordo com os dados obtidos neste trabalho, verificou-se que há um grande número de combinações de fatores climáticos que influenciam na presença de conídios no ar e, consequentemente, no desenvolvimento da doença.

\section{CONCLUSÃO}

O número de conídios de $\boldsymbol{C}$. kikuchii capturados foi maior durante o dia, entre $8 \mathrm{~h}$ e $15 \mathrm{~h}$.

A umidade relativa acima de $80 \%$ e temperatura entre $20 \mathrm{e} 24^{\circ} \mathrm{C}$ foram mais favoráveis para captura de conídios e intensidade do crestamento foliar. Há certa relação entre a intensidade de doença e o número de conídios no ar, indicando que a concentração de conídios no ar pode auxiliar no monitoramento da doença.

\section{AGRADECIMENTOS}

Os autores agradecem ao Conselho Nacional de Desenvolvimento Científico e Tecnológico (CNPq) e às Coordenação de Aperfeiçoamento de Pessoal de Nível Superior 
(CAPES), pelo financiamento parcial do estudo e pelas bolsas de estudo.

\section{REFERÊNCIAS}

BLUM, L.E.B.; DIANESE, J.C. Padrões de liberação de urediniósporos e desenvolvimento de ferrugem em jambeiro. Pesquisa Agropecuária Brasileira, v.36, p.845-850, 2001. Disponível em: <http://www.scielo.br/scielo.php?pid=S0100$204 X 2001000600001 \&$ script $=$ sci_arttext $>$. Acesso em: 20 mar. 2009. doi: 10.1590/S0100-204X2001000600001

CORREIA, M.S.; COSTA, J.L.S. Dispersão anemófila do fungo Lasiodiplodia theobromae em plantações de coqueiro. Fitopatologia Brasileira, v.30, n.2, p.150-154, 2005. Disponível em: <http://www.scielo.br/scielo.php?pid=S0100$41582005000200008 \&$ script=sci_arttext $>$. Acesso em: 22 mar. 2009. doi: 10.1590/S0100-41582005000200008.

EMBRAPA. Tecnologias de Produção de Soja - Região Central do Brasil 2009/2010 (Sistemas de Produção / Embrapa Soja, n.13). Londrina: Embrapa Soja, 2008. 262p.

FEHR, W.R.; CAVINESS, C.E. Stage of soybean development. Ames: Iowa State University, 1981. (Special report 80, March).

FERREIRA, L.P. et al. Doenças de soja no Brasil. Londrina: Embrapa Soja, 1979. 42p. (Circular Técnica 1).

FITT, B.D.L. et al. The role of rain in dispersal pathogen inoculum. Annual Review of Phytopathology, v.27, p.241-270, 1989. Disponível em: <http://arjournals.annualreviews.org/doi/abs/10.1146/ annurev.py.27.090189.001325? journalCode=phyto $>$. Acesso em: 22 mar. 2009. doi:10.1146/annurev.py.27.090189.001325.

GODOY, C.V.; CANTERI, M.G. Efeito da severidade de oídio e crestamento foliar de cercospora na produtividade da cultura da soja. Fitopatologia Brasileira, v.29, n.5, p.526-531, 2004. Disponível em: <http://www.scielo.br/scielo.php?pid=S010041582004000500009\&script=sci_arttext $>$. Acesso em: 21 jan. 2009. doi: 10.1590/S0100-41582004000500009.

HOY, J.W. et al. Production of sori and dispersal of teliospores of Ustilago scitaminea in Lousiana. Phytopathology, v.81, p.574-579, 1991. Disponível em: <http://www.apsnet.org/ phyto/PDFS/1991/Phyto81n05_574.PDF>. Acesso em: 22 mar. 2009. doi: 10.1094/Phyto-81-574.

JULIATTI, F.C. et al. Manejo integrado de doenças na cultura da soja. Uberlândia: EDUFU, 2004. 327p.

KOSHIKUMO, E.S.M. Epidemiologia da mancha de Phaeosphaeria e da cercosporiose em milho. 2007. 60f. Dissertação (Mestrado em Agronomia) - Curso de Pós-graduação em Agronomia (Produção Vegetal), Universidade Estadual Paulista, SP.

ORTH, C.E.; SHUH, W. Resistance of 17 soybean cultivars to foliar, latent, and seed infection by Cercospora kikuchii. Plant
Disease, v.78, p.661-664, 1994. Disponível em: <http:// www.apsnet.org/pd/PDFS/1994/PlantDisease78n07_661.PDF>. Acesso em: 01 fev. 2009. doi: 10.1094/PD-78-0661.

ROSSI, V. et al. Patterns of airborne conidia of Stemphylium vesicarium, the causal agent of brown spot disease of pears, in relation to weather conditions. Aerobiologia, v.21, n.3-4, p.203216, 2005. Disponível em: <http://www.springerlink.com/ content/ 765245041215t582/>. Acesso em: 19 fev. 2010. doi: 10.1007/s10453-005-9002-y.

SCHUH, W. Influence of temperature and leaf wetness period on conidial germination in vitro and infection of Cercospora kikuchii on soybean. Phytopathology, v.81, p.1315-1318, 1991. Disponível em: <http://www.apsnet.org/phyto/PDFS/ 1991/Phyto81n10_1315.PDF>. Acesso em: 01 fev. 2009. doi: 10.1094/Phyto-81-1315.

SCHUH, W. Effect of pod developing stage, temperature, and pod wetness duration on the influence of purple seed stain of soybean. Phytopathology, v.82, p.446-451, 1992. Disponível em: <http:/ /www.apsnet.org/phyto/PDFS/1992/Phyto82n04_446.PDF>. Acesso em: 01 fev. 2009. doi: 10.1094/Phyto-82-446.

SCHUH, W. Influence of interrupted dew periods, relative humidity, and light on disease severity and latent infections caused by Cercospora kikuchii on soybean. Phytopathology, v.83, n.1, p.109-113, 1993. Disponível em: <http:// www.apsnet.org/phyto/PDFS/1993/Phyto83n01_109.PDF>. Acesso em: 01 fev. 2009. doi:10.1094/Phyto-83-109.

STEPALSKA, D.; WOLEK, J. Variation in fungal spore concentrations of selected taxa associated to weather conditions in Cracow, Poland, in 1997. Aerobiologia, v.21, p.43-52, 2005. Disponível em: <http://www.springerlink.com/content/ v33gr7357j701788/fulltext.pdf>. Acesso em: 18 fev. 2010. doi: $10.1007 / \mathrm{s} 10453-004-5877-2$.

STEPALSKA, D.; WOLEK, J. Intradiurnal periodicity of fungal spore concentrations (Alternaria, Botrytis, Cladosporium, Didymella, Ganoderma) in Cracow, Poland. Aerobiologia, v.25, p.333-340, 2009. Disponível em: <http://www.springerlink.com/ c o n t e n t / $5 \begin{array}{lllllllllllllll} & 6 & 6 & 6 & \text { g } & 3 & 1 & 4 & 1 & \text { n } & 0 & \text { m } & 1 & 7 & 4\end{array}$ $? \mathrm{p}=\mathrm{c} 7 \mathrm{e} 31 \mathrm{ca} 5 \mathrm{dd} 0 \mathrm{~d} 41 \mathrm{~b} 08 \mathrm{bcd} 3$ eefc37283ef\&pi=12>. Acesso em: 18 fev. 2010. doi: 10.1007/s10453-009-9137-3.

VALE, F.X.R. et al. Influência do clima no desenvolvimento de doenças de plantas. In: VALE, F.X.R. et al. (Eds.). Epidemiologia aplicada ao manejo de doenças de plantas. Belo Horizonte: Perfil, 2004. Cap.2, p.49-80.

WALTERS, H.J. Soybean leaf blight caused by Cercospora kikuchii. Plant Disease, v.64, p.961-962, 1980.

YORINORI, J.T. Controle integrado das principais doenças da soja. In: CÂMARA, G.M.S. (Ed.). Soja: tecnologia da produção. Piracicaba: Câmara, G.M.S, 1998. p.139-192. 